\title{
THE SPECTRUM OF BONE MARROW MORPHOLOGICAL FINDINGS AND ITS DIAGNOSTIC ROLE IN EVALUATION OF HAEMATOLOGICAL DISORDERS- A RETROSPECTIVE STUDY
}

\author{
Satyasri K1, Botta Venkata Satya Kartheek², Sweta Sinha ${ }^{3}$
}

${ }^{1}$ Associate Professor, Department of Pathology, RIMS, Srikakulam, Andhra Pradesh, India.

${ }^{2}$ Assistant Professor, Department of Pathology, Andhra Medical College, Visakhapatnam, Andhra Pradesh, India.

${ }^{3}$ Consultant Pathologist, Department of Pathology, Indus Hospitals, Visakhapatnam, Andhra Pradesh, India.

\begin{tabular}{l}
\hline ABSTRACT \\
BACKGROUND \\
Bone Marrow Aspiration (BMA) is a relatively safe invasive procedure and gives excellent morphological details of marrow cellular \\
composition to assess the haematopoietic activity. \\
The objective of the present study is to evaluate the spectrum of haematological disorders diagnosed on bone marrow \\
aspiration/ biopsies in a referral centre.
\end{tabular}

\section{MATERIALS AND METHODS}

Design- A retrospective descriptive study, conducted from July $1^{\text {st }} 2016$ to $30^{\text {th }}$ June 2018.

Setting: Referral care centre in Visakhapatnam, Andhra Pradesh.

The present study included all the hospitalised patients in the age group of 0 - 85 years requiring a bone marrow examination for various haematological disorders. A total of 120 patients underwent bone marrow examination during the study period. Aspirate smears were made and stained with Leishman stain. Perls' Prussian blue stain was used for staining iron and Haematoxylin and Eosin stain was used for bone marrow trephine biopsies. Complete clinical history, physical examination and the laboratory investigations of patients who underwent bone marrow aspiration/ biopsy were noted.

\section{RESULTS}

In the current study, Erythroid hyperplasia and reactive marrow were the common findings. Immune Thrombocytopenic Purpura (ITP) is the $2^{\text {nd }}$ most common finding (12.5\%). Acute Myeloid Leukaemia (AML) constituted 8.33\% and Acute Lymphoblastic Leukaemia (ALL) constituted 6.66\% of total cases. Congenital dyserythropoietic anaemia and bone marrow fibrosis were seen in 3 $(2.5 \%)$ cases each. Haemophagolymphohistiocytosis, Myelodysplastic syndrome and Non-Hodgkin's Lymphoma were seen in 2 $(1.66 \%)$ cases each.

\section{CONCLUSION}

Evaluation of bone marrow morphological details in various haematological diseases can help physicians in appropriate management and treatment of cases.

\section{KEY WORDS}

Bone Marrow Aspiration, Bone Marrow Trephine Biopsy, Haematological Disorders, Anaemia, Erythroid Hyperplasia, Idiopathic Thrombocytopenic Purpura, Leukaemia.

HOW TO CITE THIS ARTICLE: Satyasri K, Kartheek BVS, Sinha S. The spectrum of bone marrow morphological findings and its diagnostic role in evaluation of haematological disorders- a retrospective study. J. Evolution Med. Dent. Sci. 2018;7(45):4865-4869, DOI: $10.14260 /$ jemds/2018/1084

\section{BACKGROUND}

Bone marrow examination is one of the most frequent and relatively safe invasive procedure. It is a commonly employed procedure with rarely reported incidence of bleeding, infection or embolism after trephine biopsy. ${ }^{1}$ It allows excellent morphologic evaluation of cells, differential count and myeloid-to-erythroid ratio. It gives an assessment of haematopoietic activity. ${ }^{2}$ Although, an invasive procedure, even mild-to-moderate degree of thrombocytopenia is not an absolute contraindication for bone marrow aspiration/trephine biopsy.

'Financial or Other Competing Interest': None.

Submission 25-09-2018, Peer Review 18-10-2018,

Acceptance 25-10-2018, Published 05-11-2018.

Corresponding Author:

Dr. Botta Venkata Satya Kartheek,

Consultant Pathologist,

Indus Hospitals, Maharanipeta,

Visakhapatnam-530002, Andhra Pradesh, India.

E-mail: kartheekbvs84@gmail.com

DOI: $10.14260 /$ jemds/2018/1084
Commonly, it is performed in conditions like cytopenias, leukaemias, secondary metastatic deposits in marrow and storage disorders. The spectrum of haematological disorders is relatively different in the developing world than the developed countries. ${ }^{3}$ In the current era, bone marrow biopsies have attained such a great importance that they are being employed as an important tool for the investigation of quite a number of medical disorders in medicine, especially haematology, haematological oncology and osteology. ${ }^{4}$ Conditions that affect the marrow can also affect the number, mixture, maturity of the cells and even their fibrous structure.4,5 Trephine biopsy provides a great help in recognising the aetiology of pancytopenia and is a valuable option in the diagnosis of lymphomas, osteoporosis and granulomatous disorders. 6 Trephine biopsy is indicated when a dry tap or blood tap occurs, which might be due to the fibrotic bone marrow or it is densely cellular. Trephine biopsy can permit a complete assessment of bone marrow architecture and the pattern of abnormal infiltrate distribution. It benefits well in investigating suspected 
aplastic or hypoplastic anaemia, lymphoma, metastatic carcinoma and myeloproliferative disorders. ${ }^{4}$

This study was designed to evaluate the spectrum of haematological disorders diagnosed on Bone Marrow Aspirations (BMA)/ biopsies.

\section{MATERIALS AND METHODS}

The present study is a retrospective descriptive study done in Department of Pathology, Indus Hospitals, Visakhapatnam, for a period of 2 years from July 1st 2016 to 30th June 2018. A total of 120 cases were included in this study.

\section{Inclusion Criteria}

All hospitalised patients requiring bone marrow examination for various haematological disorders were included in the study.

\section{Exclusion Criteria}

Follow-up patients of previously treated leukaemia were not part of the study.

Bone marrow aspiration reports of patients were retrieved from the medical record file in the department. Peripheral blood smear along with necessary haematological and clinical parameters were also noted from the record file. The data was manually collected and subsequently analysed.

Full aseptic measures were observed. In all cases local anaesthetic with $1 \%$ xylocaine and sedation with diazepam was given for smooth running of the procedure. The bone marrow aspiration was performed from posterior iliac crest in adults and in children above 18 months of age and from the tibia in children less than 18 months of age. Bone marrow trephine biopsy was done wherever it was indicated. A written informed consent was taken in all cases. An aspirate smear was prepared and stained with Romanowsky stain. Prussian blue stain was used for staining iron. Reticulin stain was done in cases with marrow fibrosis and graded. The slide was observed under the microscope and findings noted.

\section{RESULTS}

In the present study, a total number of 120 patients aged between 50 days and 85 years were included. 70 (58.33\%) cases were males and $50(41.67 \%)$ cases were females with $\mathrm{M}$ : $\mathrm{F}$ ratio of 1.4: 1. Maximum number of patients who underwent bone marrow aspiration in the present study were in the age group of 0 - 10 years, which constituted about 48 cases (40\%) (Table 1$)$.

In the current study, the most common indication for bone marrow aspiration was Anaemia followed by Pancytopenia. Blood counts and peripheral blood smear revealed anaemia in $41(34.16 \%)$ cases. Pancytopenia with and without fever was seen in 30 (25\%) cases. Thrombocytopenia alone was seen in $8(6.66 \%)$ cases. 21 cases $(17.5 \%)$ clinically diagnosed as Pyrexia of Unknown Origin (PUO) underwent bone marrow aspiration. Fever with associated cytopenias who underwent bone marrow aspiration were seen in 18 cases (15\%), (Table 2).

Erythroid hyperplasia and reactive marrow were the common findings in the present study with no other significant morphological findings. Megaloblastic anaemia was seen in $4(3.3 \%)$ cases. Aplastic anaemia and hypocellular marrow were seen in $5(4.16 \%)$ cases each.
Acute leukaemia was seen in $18(15 \%)$ cases. Out of this, 10 cases were Acute Myeloid Leukaemia (AML) (Figure 1) and 8 cases were Acute Lymphoblastic Leukaemia (ALL). One case who underwent bone marrow aspiration for anaemia and lytic bone lesions was diagnosed as multiple myeloma. (Figure 2). In the present study, 15 cases (12.15\%) of immune thrombocytopenic purpura were seen with characteristic megakaryocyte hyperplasia with monolobated micromegakaryocytes and hypogranular forms, (Figure 3 and 4). Congenital dyserythropoietic anaemia and bone marrow fibrosis (Figure 5 and 6 ) were seen in $3(2.5 \%)$ cases each. Haemophagolymphohistiocytosis, Myelodysplastic syndrome and Non-Hodgkin's Lymphoma (Figure 7) were seen in 2 (1.66\%) cases each, (Table 3).

\begin{tabular}{|c|c|c|c|c|}
\hline $\begin{array}{c}\text { Age in } \\
\text { Years }\end{array}$ & Males & Females & Total & Percentage \\
\hline $0-10$ & 32 & 16 & 48 & $40 \%$ \\
\hline $11-20$ & 7 & 9 & 16 & $13.33 \%$ \\
\hline $21-30$ & 1 & 2 & 03 & $2.5 \%$ \\
\hline $31-40$ & 2 & 5 & 07 & $5.83 \%$ \\
\hline $41-50$ & 7 & 8 & 15 & $12.5 \%$ \\
\hline $51-60$ & 10 & 5 & 15 & $12.5 \%$ \\
\hline $61-70$ & 5 & 4 & 09 & $7.5 \%$ \\
\hline$>70$ & 6 & 1 & 07 & $5.83 \%$ \\
\hline Total & 70 & 50 & 120 & $100 \%$ \\
\hline Table 1. Age and Sex Distribution (Total= 120 Cases) \\
\hline
\end{tabular}

\begin{tabular}{|c|c|c|}
\hline $\begin{array}{c}\text { Indications of Bone Marrow } \\
\text { Aspiration/ Biopsy }\end{array}$ & No. of Cases & Percentage \% \\
\hline Anaemia & 41 & $34.16 \%$ \\
\hline Pancytopenia & 22 & $18.33 \%$ \\
\hline Pyrexia of unknown origin & 21 & $17.5 \%$ \\
\hline Fever with pancytopenia & 8 & $6.66 \%$ \\
\hline Thrombocytopenia & 8 & $6.66 \%$ \\
\hline $\begin{array}{c}\text { Anaemia with } \\
\text { thrombocytopenia }\end{array}$ & 5 & $4.16 \%$ \\
\hline Fever with thrombocytopenia & 4 & $3.33 \%$ \\
\hline Fever with bicytopenia & 4 & $3.33 \%$ \\
\hline Hepatosplenomegaly & 2 & $1.66 \%$ \\
\hline $\begin{array}{c}\text { Splenomegaly and } \\
\text { generalised } \\
\text { lymphadenopathy }\end{array}$ & 2 & $1.66 \%$ \\
\hline $\begin{array}{c}\text { Fever with anaemia and } \\
\text { splenomegaly }\end{array}$ & 1 & $0.83 \%$ \\
\hline $\begin{array}{c}\text { Anaemia with lytic bone } \\
\text { lesions }\end{array}$ & 1 & $0.83 \%$ \\
\hline $\begin{array}{c}\text { Fever with anaemia and } \\
\text { thrombocytopenia }\end{array}$ & 1 & $0.83 \%$ \\
\hline $\begin{array}{c}\text { Table 2. Distribution of Indications for Bone Marrow } \\
\text { Aspiration among 120 Cases }\end{array}$ \\
\hline \multicolumn{2}{|c|}{} \\
\hline
\end{tabular}

\begin{tabular}{|c|c|c|c|c|}
\hline Diagnoses & Male & Female & $\begin{array}{c}\text { No. of } \\
\text { Cases }\end{array}$ & $\mathbf{\%}$ \\
\hline Erythroid hyperplasia & 10 & 8 & 18 & $15 \%$ \\
\hline Reactive marrow & 9 & 9 & 18 & $15 \%$ \\
\hline $\begin{array}{c}\text { Immune thrombocytopenic } \\
\text { purpura }\end{array}$ & 10 & 5 & 15 & $12.5 \%$ \\
\hline Normal marrow & 8 & 6 & 14 & $11.66 \%$ \\
\hline Acute myeloid leukaemia & 4 & 6 & 10 & $8.33 \%$ \\
\hline $\begin{array}{c}\text { Acute lymphoblastic } \\
\text { leukaemia }\end{array}$ & 6 & 2 & 8 & $6.66 \%$ \\
\hline Hypocellular marrow & 4 & 1 & 5 & $4.16 \%$ \\
\hline Aplastic marrow & 5 & 0 & 5 & $4.16 \%$ \\
\hline Erythroid hyperplasia- IDA & 1 & 3 & 4 & $3.33 \%$ \\
\hline
\end{tabular}




\begin{tabular}{|c|c|c|c|c|}
\hline Megaloblastic anaemia & 2 & 2 & 4 & $3.33 \%$ \\
\hline $\begin{array}{c}\text { Congenital dyserythropoietic } \\
\text { anaemia }\end{array}$ & 1 & 2 & 3 & $2.5 \%$ \\
\hline Megakaryocytic hyperplasia & 2 & 1 & 3 & $2.5 \%$ \\
\hline Bone marrow fibrosis & 1 & 2 & 3 & $2.5 \%$ \\
\hline $\begin{array}{c}\text { Haemophago- } \\
\text { lymphohistiocytosis }\end{array}$ & 0 & 2 & 2 & $1.66 \%$ \\
\hline Myelodysplastic syndrome & 2 & 0 & $Z$ & $1.66 \%$ \\
\hline Non-Hodgkin's lymphoma & 2 & 0 & 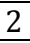 & $1.66 \%$ \\
\hline Erythroid hyperplasia- DDA & 1 & 1 & & $1.66 \%$ \\
\hline Granulomatous disease & 1 & 0 & & $0.83 \%$ \\
\hline Multiple myeloma & 1 & 0 & 1 & $0.83 \%$ \\
\hline \multicolumn{5}{|c|}{$\begin{array}{l}\text { Table 3. Spectrum of Bone Marrow Findings (Total }=120 \\
\text { Cases) }\end{array}$} \\
\hline
\end{tabular}

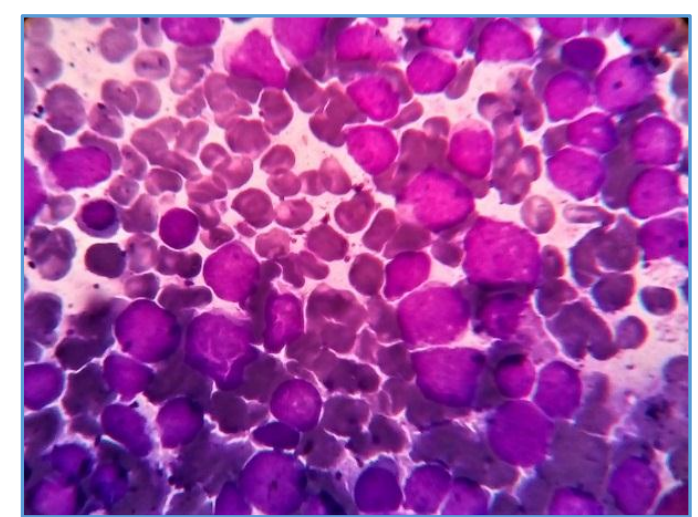

Figure 1. Acute Myeloid Leukaemia-Bone Marrow Aspirate showing Myeloblasts with prominent Nucleoli. (Leishman Stain, 1000x-Oil Immersion)

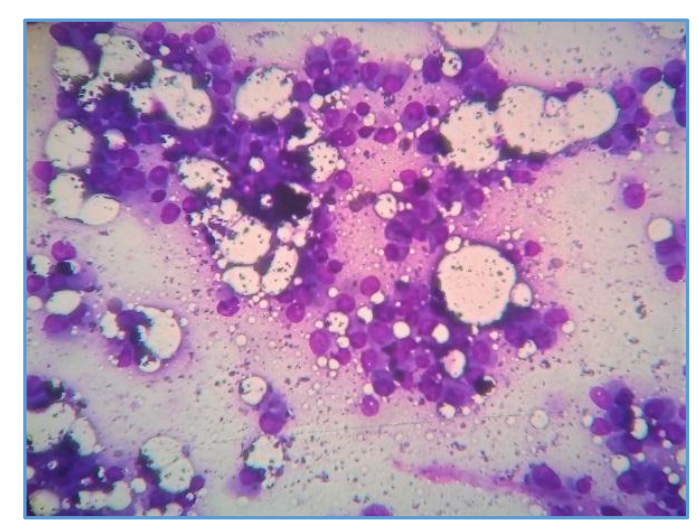

Figure 2. Multiple Myeloma: Bone Marrow Aspirate showing Atypical Plasma Cells. (Leishman Stain, 400x)

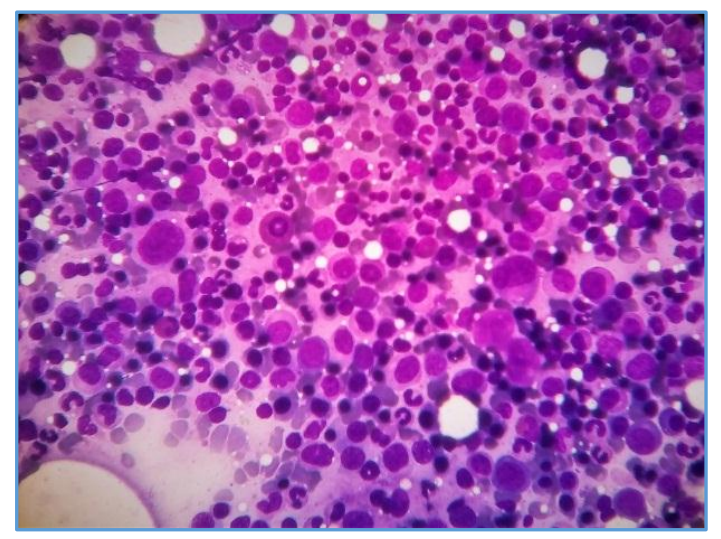

Figure 3. Immune Thrombocytopenic Purpura (ITP)- Bone Marrow Aspirate showing Immature Megakaryocytes with Unilobated Nuclei (Leishman Stain, 400x)

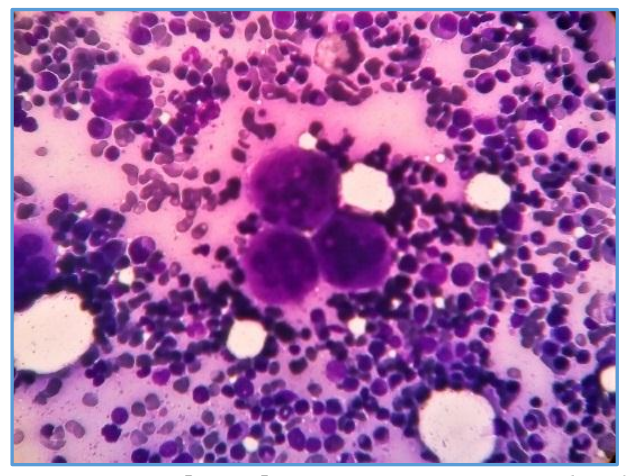

Figure 4. Immune Thrombocytopenic Purpura (ITP)- Bone Marrow Aspirate showing Megakaryocyte Hyperplasia with Clustering of Megakaryocytes. (Leishman Stain, 400x)

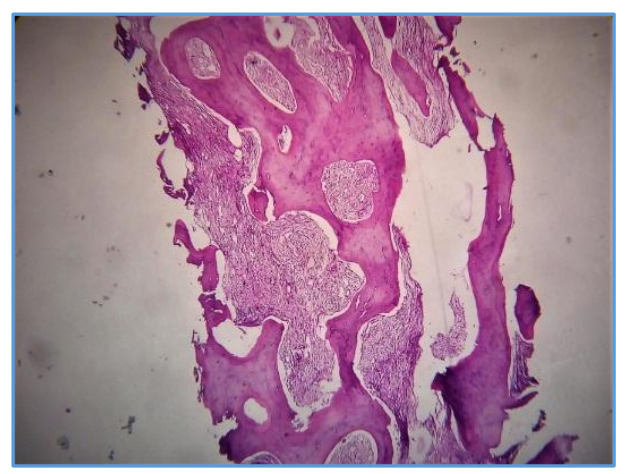

Figure 5. Bone Marrow Fibrosis: Bone Marrow Trephine Biopsy showing Extensive Fibrosis with Thickening of Bony Trabeculae. (Haematoxylin and Eosin, 100x)

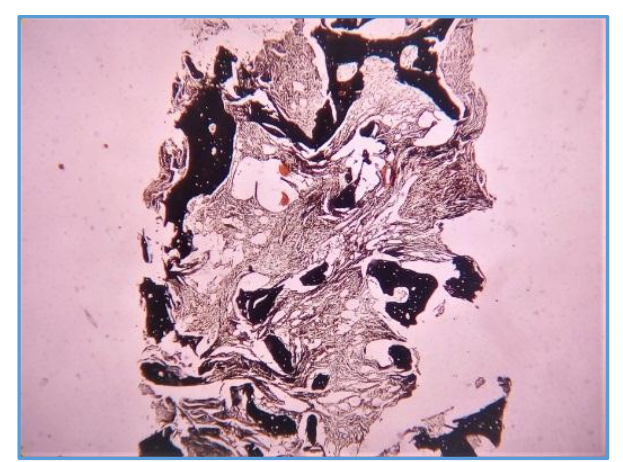

Figure 6. Bone Marrow Fibrosis: Bone Marrow Trephine Biopsy showing Grade 3 Fibrosis with Diffuse and Dense Increase in Reticulin Fibrils, Extensive Intersections and Coarse Collagen Bundles. (Reticulin Stain, Silver Impregnation Method, 100x)

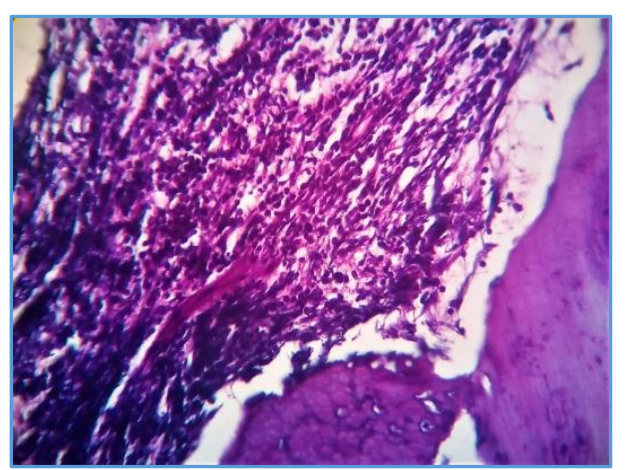

Figure 7. Non-Hodgkin's Lymphoma: Bone Marrow Trephine Biopsy showing Diffuse Replacement of the Haematopoietic Marrow by the Monotonous Population of Atypical Lymphoid Cells. (Haematoxylin and Eosin, 400x) 


\section{DISCUSSION}

Bone marrow aspiration is a useful adjunct and a diagnostic study for evaluation of various haematological disorders and final diagnosis in majority of haematological disorders is achieved after performing bone marrow aspiration or trephine biopsy, a safe and commonly employed tool in clinical practice which can be performed on an outpatient basis. ${ }^{1,2}$

Haematological disorders present as a wide range of diseases ranging from reactive hyperplasia to haematological malignancies. ${ }^{7}$

The present study was conducted to know the spectrum of haematological disorders and diagnostic value of BMA cytology examination in our hospital.

Complications of bone marrow aspiration and trephine biopsy are rare. Haemorrhage is the common complication following bone marrow aspiration and trephine biopsy. In the present study, no single case had any complications following bone marrow aspiration and trephine biopsy.

In the present study, there is M: F ratio of $1.4: 1$ with male patients who underwent bone marrow aspirations commonly. The most common age group who underwent bone marrow aspirations is between 0 - 10 years, where the youngest patient is 50 days and the oldest patient is 85 years in the present study. Our finding is similar to the study conducted by Kishore Kumar et al. ${ }^{7}$

In the current study, the most common indication for bone marrow aspiration was Anaemia (25\%) followed by Pancytopenia (18.33\%).

Similar to our findings, anaemia was the commonest indication in a study done by Ishwarsingh et al and Kishore Kumar et al; and the second common indication in a study done by Manjit Kaur et al.7,8,9

In the present study thrombocytopenia alone was seen in $8(6.66 \%)$ cases, whereas the study by Kishore Kumar et al thrombocytopenia alone was seen in $11 \%$ cases. $^{7}$

Erythroid hyperplasia (15\%) and Reactive marrow (15\%) were the common findings in the present study. Similarly, it was the commonest bone marrow finding in studies done by Pudasaini $S$ et al, $\left.{ }^{[8]}\right]$ Jha et al and Kishore Kumar et al.7,10,11

Immune Thrombocytopenic Purpura (ITP) is the 2nd most common finding (12.5\%) in the present study, both in children and the adults. In the study by Kishore Kumar et al, ITP was seen in $7.8 \%$ of the cases. In studies by Iram Ali et al, Syed Nadeem Mansoor et al and Huma Riaz ITP cases were seen in $12.85 \%, 13 \%$ and $15.7 \%$ respectively in the paediatric population. ${ }^{1,2,12}$

In the present study, all 8 cases of Acute Lymphoblastic Leukaemia (ALL) were seen in children between the age groups of 3 - 11 years. Githang'a JN et al in a study found ALL to be the commonest haematological malignancy of childhood. ${ }^{13}$ Similar results were shown by Rahim F et al. ${ }^{14}$

In developed countries, the age distribution of ALL shows a major peak at pre-school age (between 1 and 5 years of age) with a slow decline toward adolescence. ${ }^{15}$

This contrasts to the typical age distribution in less developed countries with no pre-school peak. ${ }^{16,17}$

In the present study in patients diagnosed with ALL on BMA, fever and anaemia were the common presenting complaints. In a study by Yasmeen $\mathrm{N}$ and Ashraf S on ALL, fever and pallor were the commonest presenting features. ${ }^{18}$
In the present study, 10 cases were diagnosed as Acute Myeloid Leukaemia (AML) on BMA with youngest patient being 15 years old and the oldest patient being 60 years. Majority AML patients in our study had the complaints of fever with bleeding manifestations. Biswas $\mathrm{S}$ et al noted the following features in patients of AML, fever 92.9\%, pallor $57.1 \%$, gum bleeding $42.9 \%$, bleeding from skin $42.9 \%$, lymphadenopathy $\quad 35.7 \%$, hepatomegaly $78.6 \%$, splenomegaly $66.6 \%$ and sternal tenderness $7.14 \% .{ }^{19}$

In the present study, Hypoplastic/ Aplastic marrow was seen in $10(8.33 \%)$ of cases with majority of them were seen in the adults (8 cases). 2 cases of Aplastic anaemia had dry tap on BMA, who subsequently underwent Bone marrow trephine biopsy. Aplastic anaemia is thought to be more common in Asia than in West. The patients are mostly presented with unexplained pallor, prolonged pyrexia and bleeding tendencies. Its exact aetiology is still not known, but autoimmune mechanism have been considered to have an important role in the Pathophysiology. Studies conducted worldwide have confirmed the role of exposure to toxic chemical substances and radiation in causing bone marrow failure. ${ }^{20}$

Congenital Dyserythropoietic Anaemia (CDA) was seen in $2.5 \%$ of cases. In the study by Kishore Kumar et al, CDA was seen in $0.58 \%$ of cases.

Bone marrow fibrosis indicates an increase of reticulin and collagen in the bone marrow. Such fibrosis may be focal or generalised. In the present study, $3(2.5 \%)$ cases showed marrow fibrosis on trephine biopsy. Reticulin stain revealed Grade 3 fibrosis in 2 cases and one case revealed Grade 1 fibrosis. ${ }^{21}$ In the study by Kishore Kumar et al, marrow fibrosis was seen in $2.5 \%$ of cases. $^{7}$

Haemophagocytic syndromes result from macrophage activation with increased numbers of haemophagocytic macrophages and cytopenia. Common clinical features are hepatomegaly, splenomegaly and fever. ${ }^{22}$ Two cases of Haemophago-Lymphohistiocytosis (HLH) were seen in the present study, both being under one year of age.

\section{CONCLUSION}

Bone marrow aspiration/ biopsy remains an important tool in the confirmatory diagnosis and management of various haematological and even non-haematological disorders. The main objective of this study was to know the pattern of haematological diseases in hospitalised patients in our hospital and secondly to provide a spectrum of disorders to physicians, which may guide them to initiate appropriate management and treatment.

\section{REFERENCES}

[1] Mansoor SN, Ali M, Mueez F, et al. Hematological diagnosis in children: results of a 10 year long cohort based upon bone marrow examination. P J M H S 2017;11(2):664-7.

[2] Ali I, Mir ZH, Qureshi OA, et al. Spectrum of bone marrow aspirations and their clinico-hematological profile in children. Int J Contemp Pediatr 2015;2(1):25-8.

[3] Young NS, Abkowitz JL, Luzzatto L. New insights into the pathophysiology of acquired cytopenias. Hematology Am Soc Hematol Educ Program 2000: p. 18-38. 
[4] Rashid A, Iqbal KH, Shabbir AS, et al. Spectrum of hematological disorders in children diagnosed by bone marrow aspiration/biopsy: a retrospective study in a tertiary care center. Malaysian Journal of Paediatrics and Child Health 2011;17(1):42-7.

[5] Bain BJ. Bone marrow biopsy morbidity: review of 2003. J Clin Pathol 2005;58(4):406-8.

[6] Onal IK, Sumer H, Tufan A, et al. Bone marrow embolism after bone marrow aspiration and biopsy. Am J Hematol 2005;78(2):158.

[7] Ch. Kumar K, Satyanarayanarao P, Sreedhar R, et al. Diagnostic role of bone marrow aspiration in evaluation of hematological disorders - a study of 344 cases. IOSR Journal of Dental and Medical Sciences (IOSR-JDMS) 2017;16(10):46-9.

[8] Singh I, Jain R, Gupta GN, et al. Evaluation of bone marrow for hematological anomalies in Indian pediatric and adult patients: a single tertiary care center study. IJPSR 2015;6(4):1584-9.

[9] Kaur M, Rana SAP, Kapoor S, et al. Diagnostic value of bone marrow aspiration and biopsy in routine hematology practice. Journal of Clinical and Diagnostic Research 2014;8(8):FC13-6.

[10] Pudasaini S, Prasad KBR, Rauniyar SK, et al. Interpretation of bone marrow aspiration in hematological disorders. J Path of Nepal 2012;2:30912.

[11] Jha A, Sayami G, Adhikari RC, et al. Bone marrow examination in cases of pancytopenia. J Nepal Med Assoc 2008;47(169):12-7.

[12] Riaz H, Shah MA, Azeem R. Frequency of common hematological diseases in paediatric patients presenting with clinical features indicative of bone marrow examination. KJMS 2016;9(2):197-201.
[13] Githang'a JN, Dave P. Bone marrow examination at a paediatric hospital in Kenya. East Afr Med J 2001;78(Suppl 7):37-9.

[14] Rahim F, Ahmad I, Islam S, et al. Spectrum of heamatological disorders in children observed in 424 consecutive bone marrow aspirations/biopsies. Pak J Med Sci 2005;21(4):433-6.

[15] Gurney JG, Severson RK, Davis S, et al. Incidence of cancer in children in the United States. Sex, race and 1year age-specific rates by histologic type. Cancer 1995;75(8):2186-95.

[16] Greaves MF, Colman SM, Beard ME, et al. Geographic distribution of acute lymphoblastic leukemia subtypes: second report of collaborative group study. Leukemia 1993;7(1):27-34.

[17] Stiller CA, Parkin DM. Geographic and ethnic variations in the incidence of childhood cancer. $\mathrm{Br}$ Med Bull 1996;52(4):682-703.

[18] Yasmeen N, Ashraf S. Childhood acute lymphoblastic leukaemia: epidemiology and clinicopathological features. J Pak Med Assoc 2009;59(3):150-3.

[19] Biswas S, Chakrabarti S, Chakraborty J, et al. Childhood acute leukemia in West Bengal, India with an emphasis on uncommon clinical features. Asian Pac J Cancer Prev 2009;10(5):903-6.

[20] Rosti V. The molecular basis of paroxysmal nocturnal hemoglobinuria. Haematologica 2000;85(1):82-7.

[21] Bain BJ, Clark DM, Wilkins BS. Infection and Reactive Changes. In: Bain BJ, edr. Bone marrow pathology. $4^{\text {th }}$ edn. Hoboken: Wiley-Blackwell 2010: p. 153.

[22] Bain BJ, Clark DM, Wilkins BS. Infection and reactive changes. In: Bain BJ, edr. Bone marrow pathology. $4^{\text {th }}$ edn. Hoboken: Wiley-Blackwell 2010: p. 138-40. 